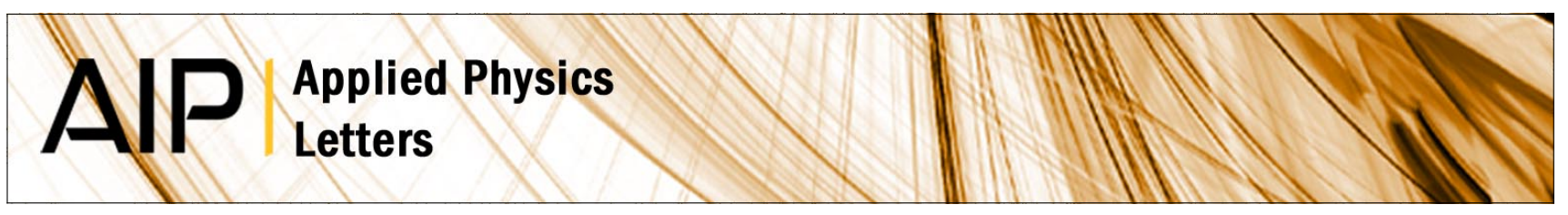

\title{
Piezoresistive strain sensing using carbon nanotube forests suspended by Parylene-C membranes
}

Anas Bsoul, Mohamed Sultan Mohamed Ali, Alireza Nojeh, and Kenichi Takahata

Citation: Appl. Phys. Lett. 100, 213510 (2012); doi: 10.1063/1.4721460

View online: http://dx.doi.org/10.1063/1.4721460

View Table of Contents: http://apl.aip.org/resource/1/APPLAB/v100/i21

Published by the American Institute of Physics.

\section{Related Articles}

Ferroelectric memristor based on $\mathrm{Pt} / \mathrm{BiFeO} / \mathrm{Nb}$-doped $\mathrm{SrTiO} 3$ heterostructure Appl. Phys. Lett. 102, 102901 (2013)

Non-volatile, reversible switching of the magnetic moment in Mn-doped $\mathrm{ZnO}$ films J. Appl. Phys. 113, 17C301 (2013)

Interference and memory capacity effects in memristive systems Appl. Phys. Lett. 102, 083106 (2013)

Design and simulation of molecular nonvolatile single-electron resistive switches J. Appl. Phys. 113, 044504 (2013)

Forming-free resistive switching memories based on titanium-oxide nanoparticles fabricated at room temperature Appl. Phys. Lett. 102, 022909 (2013)

\section{Additional information on Appl. Phys. Lett.}

Journal Homepage: http://apl.aip.org/

Journal Information: http://apl.aip.org/about/about_the_journal

Top downloads: http://apl.aip.org/features/most_downloaded

Information for Authors: http://apl.aip.org/authors

\section{ADVERTISEMENT}

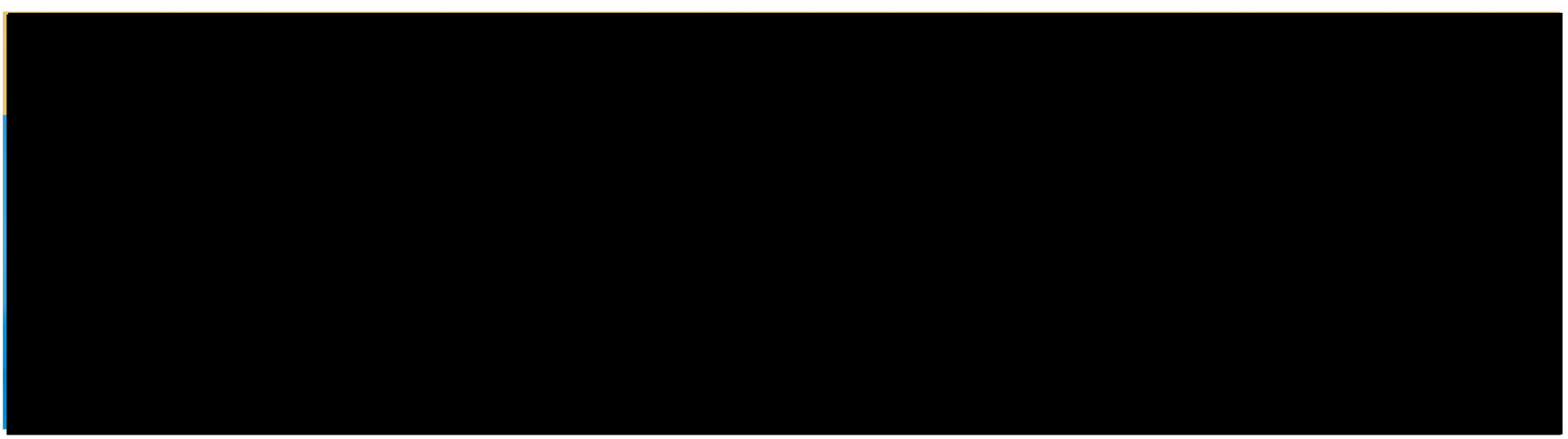




\title{
Piezoresistive strain sensing using carbon nanotube forests suspended by Parylene-C membranes
}

\author{
Anas Bsoul, ${ }^{1,2}$ Mohamed Sultan Mohamed Ali, ${ }^{1,3}$ Alireza Nojeh, ${ }^{1, a)}$ and Kenichi Takahata ${ }^{1, b)}$ \\ ${ }^{1}$ Department of Electrical and Computer Engineering, University of British Columbia, Vancouver, B.C., \\ V6T 1Z4, Canada \\ ${ }^{2}$ Department of Computer Engineering, Jordan University of Science and Technology, Irbid, Jordan \\ ${ }^{3}$ Faculty of Electrical Engineering, Universiti Teknologi Malaysia, Skudai, 81310 Johor, Malaysia
}

(Received 26 December 2011; accepted 8 May 2012; published online 24 May 2012)

\begin{abstract}
We present a strain gauge that uses a carbon nanotube (CNT) forest, partially embedded in a Parylene-C membrane, as a piezoresistor. The device exhibits high sensitivity with a gauge factor of 4.52 or higher for strains up to $\sim 1.5 \%$, offering much higher sensitivity in the strain range than those reported for other types of CNT-forest/polymer composite piezoresistors. The gauge also shows a linear response to bending strains generated by forces applied perpendicularly to the membrane with a $55-\mathrm{ppm} / \mathrm{mN}$ sensitivity. These findings suggest promising characteristics for a variety of sensing applications of the CNT-forest/Parylene film. (C) 2012 American Institute of Physics. [http://dx.doi.org/10.1063/1.4721460]
\end{abstract}

Carbon nanotubes (CNTs) have attracted considerable attention since their discovery due to their exceptional electrical, mechanical, and optical properties. ${ }^{1-3}$ The CNT forest, a collection of vertically aligned CNTs, offers unique characteristics; it can be viewed as a new class of functional bulk material with anisotropic electromechanical properties that can be utilized for many potential applications in micro-electro-mechanical systems (MEMS) and other emerging products. $^{4-9}$ The CNTs in a forest are self-aligned due to crowding at the beginning of their growth in a chemical vapor deposition (CVD) process. ${ }^{10}$ Since CNT forests can be grown directly on the substrate with the CVD technique, using them in device structures eliminates separate coating/ assembling steps for the integration of CNTs, which are required for devices that use carbon nanotube-dispersed films ${ }^{11}$ or individual CNTs. ${ }^{12,13}$ The total electrical resistance across the CNT forest in its lateral directions can strongly depend on the electrical resistances between individual CNTs. ${ }^{5}$ CNT forests are known to exhibit piezoresistivity along their lateral directions. Pressure sensors ${ }^{14,15}$ and a strain gauge ${ }^{16}$ based on this principle were recently reported. The piezoresistive effect in CNT forests has been related to the change in distances between individual CNTs due to lateral strains applied to the forest. ${ }^{14-16}$ This spatial change in CNTs may increase or decrease the number of junctions between the entangled CNTs, leading to a collective change in the lateral electrical resistance of the forest. Strain sensors based on elastomer sheets that completely embedded CNT forests were recently reported. ${ }^{16,17}$ However, there are various potential concerns in this approach, including use of wet processing, which may cause disturbance in the CNTs' alignment, ${ }^{18}$ and variations in electrical and mechanical properties of the composite elastomers affected by their curing conditions.

In this letter, we present a strain sensor that uses a multiwalled CNT forest supported by a membrane of Parylene-C,

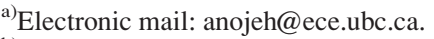

${ }^{\mathrm{b})}$ Electronic mail: takahata@ece.ubc.ca.
}

a polymer widely used in electronics and biomedical fields, deposited in gas phase with stable material properties and high thickness controllability. ${ }^{19}$ The sensor is fabricated using Si-micromachining techniques and found to offer different responses with higher performance compared with the elastomer-based devices ${ }^{16,17}$ while eliminating the need for post-growth wet processing.

The strain gauge developed in this study is designed to have a suspended membrane of Parylene-C that supports a rectangular $(2.5 \mathrm{~mm} \times 5 \mathrm{~mm}) \mathrm{CNT}$ forest (Fig. 1). The two opposing ends of the forest are contacted with the metal pads on the substrate in a manner that both ends of the forest are overlapped with the metal pads to achieve good electrical connection. When a tensile force is applied to the membrane, a strain is generated in it as well as in the forest, leading to a change in the resistance of the forest due to its piezoresistive effect, which is measured through the metal pads.

The fabrication process for the device starts from the formation of an 800-nm-thick Si-nitride mask on both sides of a Si substrate using plasma-enhanced CVD. The Si nitride on the $\mathrm{Si}$ front side is used to electrically isolate the metal pads (to be formed later) from the Si substrate. The nitride layer on the backside of the substrate is patterned to create a square window for subsequent selective etching of Si. A $20-\mathrm{nm}$ adhesive $\mathrm{Cr}$ layer followed by a $100-\mathrm{nm} \mathrm{Cu}$ film are deposited on the front side of the substrate and patterned with a lift-off step to form the metal pads on the substrate. A

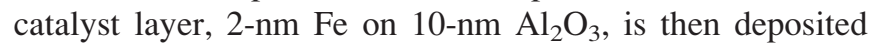
and patterned in a similar manner to define the region where the CNT forest will be grown. An atmospheric-pressure CVD system is used to grow a forest to the height of $400-600 \mu \mathrm{m}$ using $\mathrm{C}_{2} \mathrm{H}_{4}$ as the carbon source. Next, an $8-\mu \mathrm{m}$ Parylene-C film (Specialty Coating Systems, IN, USA) is deposited on the substrate including the forest of CNTs whose tops are tied together by the deposited Parylene film. The $\mathrm{Si}$ substrate is then dry etched with $\mathrm{XeF}_{2}$ through the backside window of the Si-nitride mask, releasing the Parylene membrane with the CNT forest. Finally, the nitride layer left on 


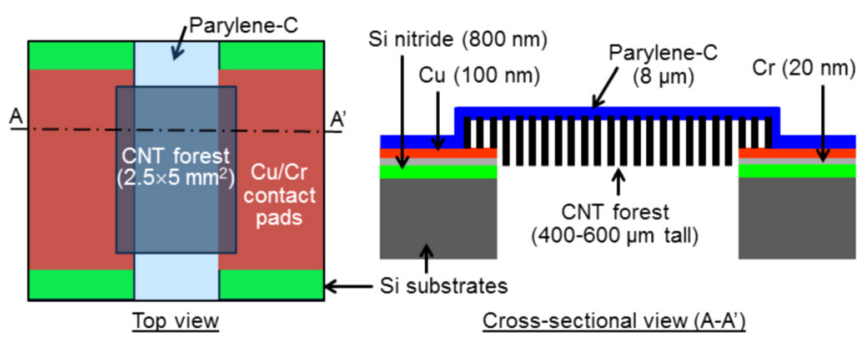

FIG. 1. Top and cross-sectional views of the piezoresistive strain gauge with CNT forest suspended from Parylene membrane.

the backside of the forest is stripped by dry etching to complete the fabrication. Figure 2 shows a typical sensor fabricated using the above process.

The piezoresistive responses of the fabricated devices to axial strains were measured while stretching the released membrane using a precision linear stage by displacing (in $10-\mu \mathrm{m}$ steps) one side of the Si substrate with respect to the other side that was fixed. A laser displacement sensor (LK-G32, Keyence, ON, Canada, with a resolution of $10 \mathrm{~nm}$ ) was used to characterize the actual displacements of the stage and verify the accuracy of the stage for the full displacement range tested in this study. Figure 3 shows the measured relative resistive changes, $\Delta R / R$, showing increases of the electrical resistance with the displacement over five measurement cycles. Assuming that the Parylene film on the substrates was perfectly stationary without any slipping (i.e., the entire displacement was applied to the suspended film), the measured result suggests the gauge factor of 4.52 for up to around $35 \mu \mathrm{m}$ displacement (corresponding to $\sim 1.5 \%$ strain), which is $\sim 13.3 \times$ the value reported for the CNT-forest/polyurethane composite sheet $^{17}$ and $\sim 3.8 \times$ the

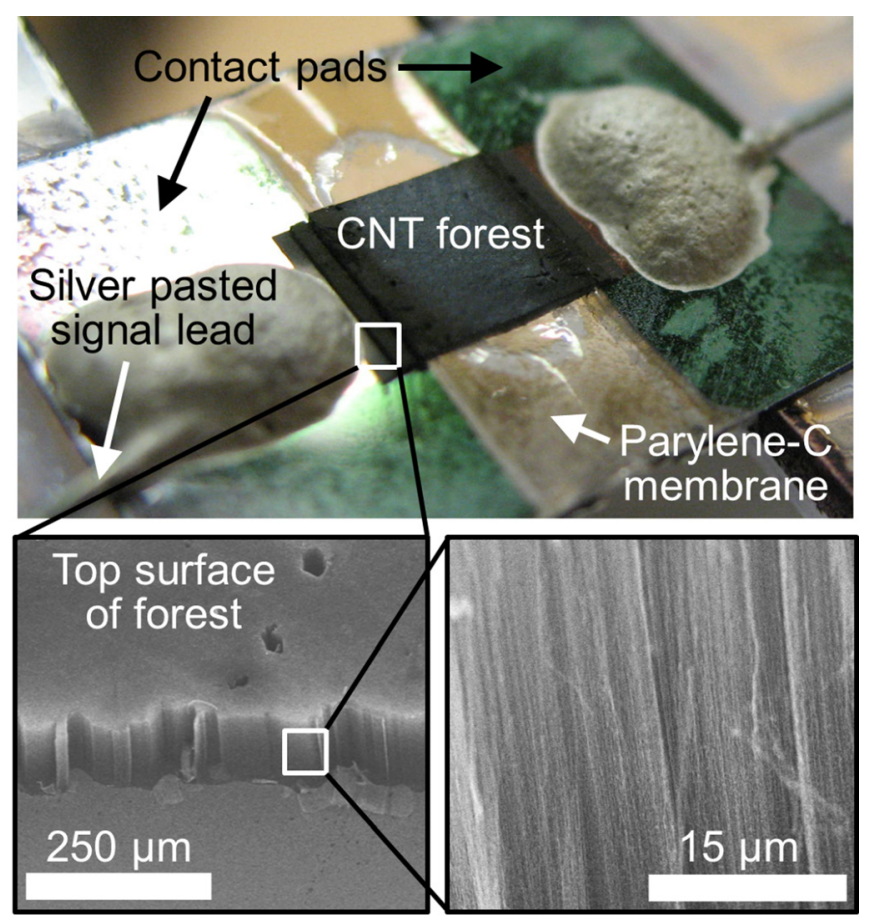

FIG. 2. Optical image of a fabricated sample device (upper) with two scanning electron microscope (SEM) images of close-ups of the CNT forest (lower).

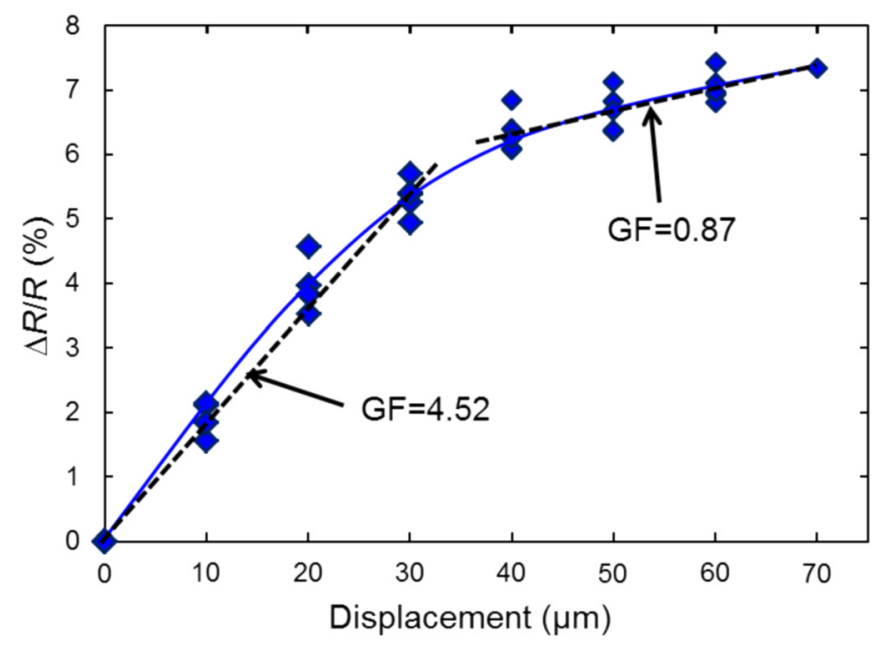

FIG. 3. Measured $\Delta R / R$ of the fabricated strain gauge with displacements up to $70 \mu \mathrm{m}$. The gauge-factor (GF) values shown are calculated under the assumption that the entire displacement was applied to the suspended membrane.

value reported for the CNT-forest/PDMS strain sensor. ${ }^{16}$ As can be seen in Fig. 3, the sensor response was observed to decrease (to a gauge factor of 0.87 under the same assumption) for displacements beyond $\sim 35 \mu \mathrm{m}$. It is worth noting that if there is any slipping effect on the substrates as noted above, it will effectively reduce the strain applied to the forest, i.e., the actual gauge factors will be larger than the values obtained above. Both high and low sensitivity regions exhibit approximately linear responses. The collected results from different rounds were found to have reasonable repeatability, indicating that the deformation is elastically reversible (i.e., no viscoelastic response), an important feature for the application of interest.

The device response was also characterized in the bending mode, in which the Parylene membrane (on the side without the forest) was pressed by a cylindrical rod (diameter equal to $\sim 60 \%$ of the membrane length) while the two Si substrates were stationary (Fig. 4(a)). Figure 4(a) shows $\Delta R / R$ and vertical force applied to the membrane (measured using a digital force gauge with $1 \mathrm{mN}$ resolution (DS2-1, Imada Inc., IL, USA)) as a function of the vertical displacement of the rod, indicating nonlinear responses in both $\Delta R / R$ and vertical force. It can be found from the same data replotted in Fig. 4(b) that there is a good linear relationship between $\Delta R / R$ and the force with a sensitivity of $55 \mathrm{ppm} / \mathrm{mN}$ over the tested range, a promising characteristic towards force sensing applications of this device configuration.

In summary, we have demonstrated a strain gauge enabled by a piezoresistive effect in $\sim 500-\mu$ m-tall, multiwalled CNT forests suspended from a thin film of Parylene-C. We fabricated the sensor through a Si-micromachining approach and found gauge factors of at least 4.52 and 0.87 for high sensitivity and lower sensitivity regions, respectively, with the fabricated devices. The bending-mode testing of the sensor revealed a high linearity in its response to applied forces. We expect that these findings will serve as a basis towards the realization of CNT-forest-based strain and force sensors and encourage further developments. 

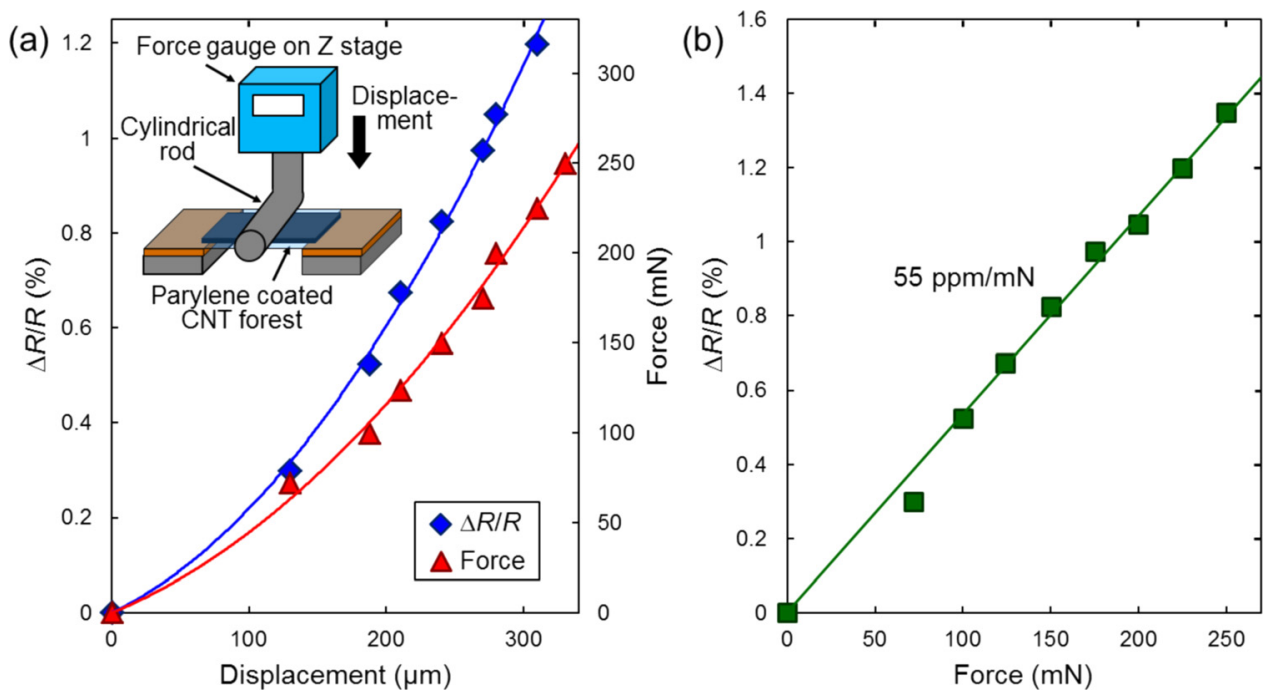

FIG. 4. (a) Measured $\Delta R / R$ of the fabricated strain gauge and force applied in response to bending of the forestParylene membrane, with an inset of a schematic diagram of the bending test set-up. (b) Measured $\Delta R / R$ vs. force showing a linear response of the device to the bending force.
We thank Tanveer Saleh and Masoud Dahmardeh for their assistance in sample preparation. This work was partially supported by the Natural Sciences and Engineering Research Council of Canada. K. Takahata is supported by the Canada Research Chairs program. A. Bsoul acknowledges financial support from Jordan University of Science and Technology. M. S. Mohamed Ali acknowledges financial support from Ministry of Higher Education Malaysia and Universiti Teknologi Malaysia.

${ }^{1}$ T. W. Odom, J.-L. Huang, P. Kim, and C. M. Lieber, J. Phys. Chem. B 104, 2794 (2000).

${ }^{2}$ P. Avouris and J. Chen, Mater. Today 9, 46 (2006).

${ }^{3}$ H. Dai, Surf. Sci. 500, 218 (2002).

${ }^{4}$ D. N. Hutchison, N. B. Morrill, Q. Aten, B. W. Turner, B. D. Jensen, L. L. Howell, R. R. Vanfleet, and R. C. Davis, J. Microelectromech. Syst. 19, 75 (2009).

${ }^{5}$ Y. Jiang, P. Wang, and L. Lin, in 24th IEEE International Conference on Micro Electro Mechanical Systems (IEEE MEMS), Cancun, Mexico, 23-27 January 2011, pp. 396-399.

${ }^{6}$ Y. Hayamizu, T. Yamada, K. Mizuno, R. C. Davis, D. N. Futaba, M. Yumura, and K. Hata, Nat. Nanotechnol. 3, 289 (2008).

${ }^{7}$ K. Kordás, G. Tóth, P. Moilanen, M. Kumpumäki, J. Vähäkangas, A. Uusimäki, R. Vajtai, and P. M. Ajayan, Appl. Phys. Lett. 90, 123105 (2007).
${ }^{8}$ M. Chhowalla, C. Ducati, N. L. Rupesinghe, K. B. K. Teo, and G. A. J. Amaratunga, Appl. Phys. Lett. 79, 2079 (2001).

${ }^{9}$ L. Ge, S. Sethi, L. Ci, P. M. Ajayan, and A. Dhinojwala, Proc. Natl. Acad. Sci. 104, 10792 (2007).

${ }^{10}$ E. Verploegen, A. J. Hart, M. D. Volder, S. Tawfick, K.-K. Chia, and R. E. Cohen, J. Appl. Phys. 109, 094316 (2011).

${ }^{11}$ L. Yong, W. Wanlu, L. Kejun, H. Chenguo, H. Zhi, and F. Qing, Chin. Sci. Bull. 48, 125 (2003).

${ }^{12}$ C. Stampfer, T. Helbling, D. Obergfell, B. Schöberle, M. K. Tripp, A. Jungen, S. Roth, V. M. Bright, and C. Hierold, Nano Lett. 6, 233 (2006).

${ }^{13}$ M. Q. H. Zhang, C. K. M. Fung, G. C. T. Chow, W. J. Li, and P. Leong, in 6th IEEE Conference on Nanotechnology (IEEE-NANO), Cincinnati, USA, 17-20 July 2006, pp. 802-805.

${ }^{14}$ C.-M. Lin, L.-Y. Lin, and W. Fang, in 23rd IEEE International Conference on Micro Electro Mechanical Systems (IEEE MEMS), Wanchai, Hong Kong, 24-28 January 2010, pp. 55-58.

${ }^{15}$ A. Bsoul, M. S. M. Ali, and K. Takahata, IET Electron. Lett. 47, 807 (2011).

${ }^{16}$ G. Keulemans, F. Ceyssens, M. D. Volder, J. W. Seo, and R. Puers, in 21st Micromechanics and Micro systems Europe Workshop (MME), Entschede, The Netherlands, 26-29 September 2010, pp. 231-234.

${ }^{17}$ M. K. Shin, J. Oh, M. Lima, M. E. Kozlov, S. J. Kim, and R. H. Baughman, Adv. Mater. 22, 2663 (2010).

${ }^{18}$ W. Khalid, M. S. M. Ali, M. Dahmardeh, Y. Choi, P. Yaghoobi, A. Nojeh, and K. Takahata, Diamond Relat. Mater. 19, 1405 (2010).

${ }^{19}$ J. B. Fortin and T.-M. Lu, Chemical Vapor Deposition Polymerization: The Growth and Properties of Parylene Thin Films (Academic, Kluwer, 2004). 